\title{
Article \\ Analysis of Behavioral Strategies of Construction Safety Subjects Based on the Evolutionary Game Theory
}

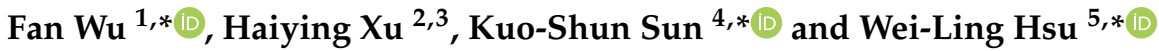 \\ 1 Business School, Hohai University, Nanjing 211100, China \\ 2 School of Urban and Environmental Science, Huaiyin Normal University, Huai'an 223300, China; \\ xuhaiying@hytc.edu.cn \\ 3 Key Research Base of Philosophy and Social Sciences of Colleges \& Universities in Jiangsu Province, \\ Research Institute of Huai River Eco-Economic Belt, Huai'an 223300, China \\ 4 Department of Air Transportation, Kainan University, Taoyuan 33857, Taiwan \\ 5 School of Civil Engineering, Jiaying University, Meizhou 514015, China \\ * Correspondence: 191313070041@hhu.edu.cn (F.W.); kssun@mail.knu.edu.tw (K.-S.S.); \\ 8201811011@hytc.edu.cn (W.-L.H.)
}

check for updates

Citation: Wu, F.; Xu, H.; Sun, K.-S.; Hsu, W.-L. Analysis of Behavioral Strategies of Construction Safety

Subjects Based on the Evolutionary Game Theory. Buildings 2022, 12, 313. https://doi.org/10.3390/ buildings 12030313

Academic Editor: Paulo Santos

Received: 29 January 2022

Accepted: 4 March 2022

Published: 6 March 2022

Publisher's Note: MDPI stays neutral with regard to jurisdictional claims in published maps and institutional affiliations.

Copyright: (C) 2022 by the authors. Licensee MDPI, Basel, Switzerland. This article is an open access article distributed under the terms and conditions of the Creative Commons Attribution (CC BY) license (https:// creativecommons.org/licenses/by/ $4.0 /)$

\begin{abstract}
In construction safety management practices, identifying key stakeholders and specifying their safety behavior patterns are critical to avoid unsafe practices, which are the major cause of construction accidents. This paper argues that the main contractor and construction workers are key safety stakeholders in the construction safety management in China. The purpose of this paper is to develop an evolutionary game model to explore the safety behavior strategies of the main contractor and construction workers. In this framework, we explored the effects of model parameter changes on the evolution of safety behavior strategies and verify the evolution paths under different initial values by numerical simulations. The findings of this paper are as follows: Firstly, the safety and stability of construction projects are related to the possible losses caused by accidents, the amount of work required by construction workers to comply with safety regulations, the gain of bravado, the probability of accidents, and cost savings from the main contractor's lax supervision. Secondly, the role of restraining the unsafe behavior of construction workers through the form of fines is limited, and increasing the fines to the main contractor cannot effectively reduce the unsafe behaviors. Thirdly, strengthening safety education, creating a safe atmosphere, and optimizing operating procedures are effective measures to improve the effectiveness of safety behavior. This study further extends the application of evolutionary game theory to construction safety management, and the findings can provide clear guidance for the development of effective incentives and constraints on safety behavior.
\end{abstract}

Keywords: evolutionary game model; the main contractor; construction workers; safety behavior strategies; construction safety management

\section{Introduction}

The World Health and Safety Executive Report states that the construction industry is the most important industry responsible for high injury and fatality rates in both developing and developed countries [1-3]. The construction industry has contributed significantly to the economic growth in many countries. However, this sector has a very high accident rate. According to the document "Notice on Special Treatment of Production Safety Accidents and Building Construction Safety in Housing and Municipal projects" issued by the General Office of the Ministry of Housing and Urban-Rural Development of China [4], the number of construction safety accidents in housing and municipal projects in China increased year by year during 2015-2019. In 2019, the number of accidents was as high as 904, resulting in 773 deaths. The number of safety accidents and fatalities is maintained at a high level. Thus, there are still many urgent issues to be solved in construction safety management in China. 
The successive promulgation of documents such as the Law of the People's Republic of China on Work Safety, the Opinions of the Central Committee of the Communist Party of China, and the State Council on Promoting the Reform and Development of the Field of Work Safety, and the "14th Five-Year Plan for Work Safety" shows that the construction industry has begun to pay more and more attention to work safety and safety management issues [5]. The practice of safety management can not only improve working conditions but also positively influence employees' attitudes and behaviors about safety, thereby reducing accidents in the workplace $[1,6]$.

Construction projects generally involve multiple actors, including the owner, supervisor, the main contractor, construction workers, etc. The question of who is responsible for the safety of the project is directly related to the performance of safety management. The unsafe behavior of construction workers is of course the direct reason leading to safety accidents on construction sites, but superior management is the root cause of safety accidents. Therefore, the owner, supervisor, and the main contractor should all be responsible for the occurrence of safety accidents $[7,8]$. The owner is the senior leader in the project. The role of the owner is particularly important when the main contractor is not effective in safety management [9]. Wu et al. [7] provided a comprehensive explanation of the role of the owner in construction safety and believed that the greatest role of the owner is to influence the safety awareness, motivation, and behavior of other stakeholders.

However, China has a long history of implementing contractor-oriented safety management. In the relevant laws, regulations, and related contract conditions, it is stipulated that the main contractor is the responsible party for construction safety, while the owner's responsibility for production safety is not directly stipulated. According to the relevant regulations in China and the model contract conditions prepared by Fédération Internationale Des Ingénieurs-Conseils (FIDIC), Institution of Civil Engineers (ICE), and American Institute of Architect (AIA), He et al. discussed the responsibilities of the main contractor, owner, and supervisor in safety management in detail [10]. They believed that the main contractor and the representative assigned to implement the project at the site (i.e., the project manager assigned to the site by the main contractor) are responsible for the safety of the site, while the owner and the supervisor are not responsible for the construction safety and safety accidents, except in a few special cases specified in the law.

In summary, China's construction safety management needs urgent improvement, and some scholars disagree on the definition of the main body of construction safety. This paper argues that the main stakeholders of construction safety include construction workers and the main contractor. Therefore, we explored the behavioral strategies of the two safety actors. This paper consists of five parts. Section 2 summarizes the game relationship between the safety behaviors of the main contractor and construction workers based on the literature review. Section 3 develops an evolutionary game model and finds the equilibrium point of the model. Section 4 uses MATLAB (an acronym for "MAtrix LABoratory", MathWorks, Na-tick, MA, USA) [11] to simulate and analyze the effects of each variable on the model. In Section 5, we propose some effective countermeasures for the management of safety behaviors. We expect this study to expand the application of evolutionary game theory in construction safety management on the one hand and hope that the results of the study will be a guide to develop effective incentives and constraints for safety behaviors on the other hand.

\section{Literature Review}

2.1. The Characteristics of Safety Behaviors of the Main Contractor and Construction Workers and Their Game Relationship

Safety behavior refers to the degree of compliance with safety regulations and the degree of participation in safety activities exhibited by the behavior subject at the worksite, which is difficult to predict and control $[12,13]$. As stated in Section 1, the main contractor and construction workers are the main stakeholders for construction safety management in China. Construction workers are the direct implementers of safety behaviors, and the main 
contractor's safety supervision is mainly aimed at construction workers. Next, we analyze the safety behavior characteristics of the main contractor and construction workers separately.

The main contractor must reduce construction accidents and negative environmental impacts to comply with regulatory requirements and remain competitive $[14,15]$. The main body of the main contractor's safety behavior is the project management team, which consists of two parts, i.e., the old employees who are promoted from the grass-roots construction workers to the management and the university graduates with higher educational backgrounds [16]. At this stage, the project management team of the main contractor usually has a relatively high level of education and learning ability, has a relatively comprehensive operating experience and technology, and has certain organizational management capabilities.

Their understanding and attitude towards safe work mainly depend on the corporate culture, the corporate safety production system, and the supervision of the superiors. With the emphasis on safety production and safety management in China, the willingness of the main contractor to be safe is usually very strong. However, the construction industry products are single pieces, and the production process is also staged. The improvement of the safety management level of the main contractor also means an increase in the production cost. Therefore, the main contractor is not motivated to improve safety management based on the goal of maximizing profits; in special circumstances, such as rush schedules, they may also not strictly supervise.

As the direct implementers of safety behaviors, construction workers subjectively attach great importance to their own safety. However, in China, construction workers generally have low education level, poor learning ability, and poor organization and discipline. [17,18]. Chinese Investigation Reports of Local Safety Bureaus [19-21] show that the following factors can cause unsafe behaviors of construction workers: (1) Construction workers lack safety awareness or knowledge of safety regulations, resulting in their weak capability of risk identification. (2) Construction workers may violate safety regulations to save energy and physical effort and increase personal labor productivity. (3) Construction workers may violate safety regulations due to the mentality of bravado. (4) Construction workers may violate safety regulations due to herd mentality. When some people violate the regulations, especially when there are no penalties for violating the regulations and no workplace accidents, the propensity for others to violate the safety regulations becomes more prominent.

Overall, there are differences in project role and safety perceptions of the two main participant groups, namely, the main contractor and construction workers in all aspects of project start-up and construction, and there also are differences in the goals of the two main safety actors. The ultimate goal of the main contractor is to deliver the project entity to the owner on time, while the goal of construction workers is to complete their workload with as little physical effort as possible. The mutual collaboration in this different state and the safety actions taken in the same site condition reflect the game relationship between the two groups.

\subsection{Game Theory in the Study of Construction Safety Management}

Game theory is a mathematical framework for analyzing strategic choices based on expected benefits [22,23]. Safety actors in construction projects often have game relations of interest, so many scholars argue that game theory can effectively analyze the decisionmaking behaviors of all stakeholders in construction safety management. Sun [24] first introduced game theory to analyze the problem in the field of construction safety in China, and he argued that the safety management of construction projects be a complex cooperative system, and the safety objectives of the system be accomplished on the basis of a binding agreement and win-win situation for all participants, i.e., the cooperative game model in game theory. Chen [25] developed a four-party game model with contractors, supervisory engineers and government regulators as the interest subjects, and conducted quantitative analysis through the game matrix to study the causes of construction safety. 
He et al. [8] analyzed two types of safety behaviors with the game theory based on the perspective of three responsible subjects, namely, the owner, the main contractor, and construction workers. Xiao and Sun [26] established a game model of construction project safety management and conducted two-by-two game analysis on government and construction enterprises, construction enterprises and construction enterprises, and construction enterprises and construction employees, respectively. Most of these studies are based on static game analysis, which is difficult to truly reflect the decision-making process and laws of safety actors in the project management process, so the proposed safety management strategies do not have sufficient guidance value for realistic problem solving.

Safety actors in construction projects continue to play games based on their own interests and continuously make safety strategy adjustments [27]. Thus, some scholars used evolutionary game theory to study the formation mechanism of safety management equilibrium. For example, Chen et al. [28] used the evolutionary game theory to analyze the characteristics of evolutionary game behavior between the main contractor and the safety supervision departments in tunnel projects. Feng et al. [29] took the supervision of construction safety in China as the research object and established a rent-seeking evolutionary game model between the state, government safety supervision department, the main contractor, and other rational stakeholders with boundaries. Cheng and Chen [30] analyzed the interaction process between the safety behavior of construction enterprises and the regulatory behavior of governmental supervisors using the evolutionary game approach.

It can be seen that the application of game theory in the field of construction safety management has been continuously expanded, from static game to dynamic game. However, the above literatures reveal that scholars disagree on the definition of game subjects for construction safety management, and there are too many safety actors, which leads to unclear guidance of research findings for China's construction safety management. In this paper, only the two key safety stakeholders in construction projects are analyzed in the evolutionary game.

Notably, the existing literature differs not only in the subjects of the game but also in the research results. For example, Chen et al. [31] argued that increasing the punishment for unsafe behavior of construction workers can more effectively control the unsafe behavior of construction workers. However, Liu et al. [10] argued that adopting a "blunt" approach to safety management, i.e., limiting employees' unsafe behaviors using fines, has limited effect. Scholars are somewhat divided on whether fines can effectively control construction workers' unsafe behaviors. This paper also hopes to explore whether fines can play an effective role in construction safety through the evolutionary game theory method.

\section{Methodology}

\subsection{Evolutionary Game Theory}

Many methods have been utilized to study construction safety management. For example, Ma et al. [32] used machine learning to synthesize construction safety risk factors. $\mathrm{Yi}$ and $\mathrm{Wu}$ [33] reviewed the application of combined artificial intelligence and big data for safety management in construction projects. Dasandara and Dissanayake [34] used the questionnaire to study the use of personal protective equipment by construction workers for restrictive reasons. Chen et al. [35] used the evolutionary game theory to study the safety supervision of tower crane operations in construction sites.

In this paper, two aspects are considered to choose to study construction safety management based on the evolutionary game theory. One is the reality of the game relationship between the two stakeholders of construction safety. Second, because the construction period is generally long, the game relationship between the two has a dynamic and long-term nature.

The evolutionary game theory is a theoretical approach that combines game theory analysis and dynamic evolutionary process analysis. It emphasizes a dynamic equilibrium, which is different in approach from game theory, which focuses on static equilibrium and comparative static equilibrium. Both parties of the game are finite rational, and both parties cannot find the optimal strategy and the optimal equilibrium point at the beginning. 
Thus, in the process of the game, both parties need to learn continuously, and gradually correct any strategic mistakes and imitate others' favorable strategies. After a period of imitation and error correction, both parties of the game will converge on a stable strategy. The evolutionary game theory has been applied in many research fields. For example, $\mathrm{Ni}$ et al. [36] studied nuclear safety management based on the evolutionary game theory and Rank-Dependent Expected Utility theory. Huang et al. [37] studied the incentive policy for assembled houses in China based on the evolutionary game theory. Zhu et al. [38] investigated how policy interventions under different quota objectives affect the behavioral strategies of stakeholders involved in the renewable portfolio standard based on the evolutionary game theory. The assumptions of the game relationships are the same across research areas, but the competitive relationships are different.

\subsection{Model Hypothesis}

This paper argues that the safety behavior game mainly occurs in the main contractor and construction workers. Construction workers may choose the strategy to comply with safety production regulations or violate rules and regulations, that is, $X=$ (safe operation $(X 1)$, illegal operation $(X 2))$. The main contractor may choose the strategy of strict safety management or non-strict safety management, that is, $Y=($ strict supervision $(Y 1)$, non-strict supervision $(Y 2))$. The game strategies of both parties include four situations, i.e., $(X 1, Y 1),(X 1, Y 2)$, $(X 2, Y 1)$, and $(X 2, Y 2)$.

Hypothesis 1. The safety quality of construction workers is low, and they do not know enough about the risk. Construction workers will violate rules and regulations for their benefit such as saving physical strength and energy and increasing labor productivity. Construction workers will be influenced by the group and violate regulations due to the mentality of bravado and herd mentality.

Hypothesis 2. Construction workers are in a state of limited rationality to maximize their interests.

Hypothesis 3. The main contractor strictly follows the system management, which means that the main contractor can accurately grasp the situation of construction workers' violation of rules through inspection and give certain punishment according to the regulations.

Hypothesis 4. The main contractor is in a state of limited rationality and aims to pursue their maximum interests.

\subsection{Relevant Parameters}

Assumptions were made about the profit and loss variables for each participant, which are the relevant parameters in the game model. The specific explanations of these parameters are shown in Table 1. The ultimate gain of the construction workers' safe operation is $A$, and the ultimate gain of the main contractor's strict safety management is $B$. The contractor's potential management cost savings due to lax supervision is $C 1$. The non-compliant operation of construction workers will save a certain amount of labor, and at the same time, it will gain psychological or spiritual recognition for showing off or following the behavior of the construction workers.

Table 1. Parameters in evolutionary game model.

\begin{tabular}{cc}
\hline Parameter Symbols & Explanation of Parameters \\
\hline$A$ & Ultimate gain of the construction workers' safe operation \\
$C 1$ & Ultimate gain of the main contractor's strict safety management \\
$D$ & Financial penalties are given by the main contractor to construction workers with the non-compliant operation \\
$F$ & Financial penalties to the main contractor for non-strict supervision \\
$K$ & Probability of the accident \\
$S 1$ & Losses to be borne by construction workers when the accident occurs \\
$S 2$ & Losses to be borne by the main contractor when the accident occurs \\
$t$ & Time
\end{tabular}


This part of the additional gain is set as D. If the main contractor conducts inspections, the non-compliant operation of construction workers will be corrected, and construction workers will receive a fine $F$ from the main contractor. If the main contractor does not have strict supervision, they will receive a penalty $K$ from the owner. The probability of the accident is $\alpha$. When the accident occurs, the construction workers must bear a certain loss, which is set as $S 1$, and the loss of the main contractor is $S 2$.

Based on the assumptions of the model, the gain matrix of the game between the main contractor and construction workers can be obtained, as shown in Table 2.

Table 2. Gain matrix of the game between the main contractor and construction workers.

\begin{tabular}{|c|c|c|c|}
\hline & & \multicolumn{2}{|c|}{ The Main Contractor } \\
\hline & & Y1 Strict Supervision $(q)$ & Y2 Non-Strict Supervision $(1-q)$ \\
\hline \multirow{2}{*}{ Construction workers } & $\begin{array}{c}\text { X1 Safe } \\
\text { operation }(p)\end{array}$ & $A B-C 1$ & $A B-K$ \\
\hline & $\begin{array}{l}\text { X2 Non-compliant operation } \\
\qquad(1-p)\end{array}$ & $A+D-F, B-C 1$ & $A+D-\alpha(S 1), B-K-\alpha(S 2)$ \\
\hline
\end{tabular}

\subsection{Construction of the Evolutionary Game Model}

According to the above game relationship, the replication dynamic equation of the evolutionary game between the main contractor and construction workers was constructed. The proportion of construction workers who choose safe operations is $p$, and the proportion of non-compliant operations is 1- $p$. The probability of strict supervision is $1-q$, the gains of construction workers who choose safe operations and non-compliant operations are $U 1$ and $U 2$, respectively, and the average gain of construction workers is $U$. The gains of the main contractor who chooses strict supervision and non-strict supervision are $V 1$ and $V 2$, respectively, and the average gain of the main contractor is $V$.

(1) The game strategy of the construction workers is:

$$
\begin{gathered}
U 1=A q+A(1-q)=A \\
U 2=(A+D-F) q+(A+D-\alpha S 1)(1-q)=A+D-\alpha S 1+(\alpha S 1-F) q \\
U=p U 1+(1-p) U 2
\end{gathered}
$$

(2) The game strategy of the main contractor is:

$$
\begin{gathered}
V 1=(B-C 1) p+(B-C 1)(1-p)=B-C 1 \\
V 2=(B-K) p+(B-K-\alpha S 2)(1-p)=B-K-\alpha S 2+\alpha S 2 p \\
V=q V 1+(1-q) V 2
\end{gathered}
$$

The replication dynamic equations of the construction workers and the main contractor are

$$
\begin{gathered}
F(p)=d p / d t=p(U 1-U)=p(1-p)(U 1-U 2)=p(1-p)((F-\alpha S 1) q-D+\alpha S 1) \\
G(q)=d q / d t=q(V 1-V)=q(1-q)(V 1-V 2)=q(1-q)(F-C 1+K+\alpha S 2-\alpha S 2 p)
\end{gathered}
$$

The Jacobi matrix of the evolutionary game is:

$$
\begin{gathered}
J=\left[\begin{array}{cc}
d F(p) / d p & d F(p) / d q \\
d G(q) / d p & d G(q) / d q
\end{array}\right] \\
J=\left[\begin{array}{cc}
(1-2 p)((F-\alpha S 1) q-D+\alpha S 1) & p(1-p)(F-\alpha S 1) \\
-q(1-q) \alpha S 2 & (1-2 q)(F-C 1+K+\alpha S 2-\alpha S 2 p)
\end{array}\right]
\end{gathered}
$$

\subsection{Evolutionary Equilibrium and Stability Analysis}

On the plane $M=\{0 \leq p \geq 1,0 \leq q \geq 1\}$, five equilibrium points of the evolutionary game can be obtained, i.e., $E 1(0,0), E 2(0,1), E 3(1,0), E 4(1,1)$ and $E 5\left(p^{*}, q^{*}\right)$, when $p^{*}, q^{*}$ $\in[0,1]$, and $E 5$ exists. 
The determinant and trace of the Jacobian matrix are:

$$
\begin{gathered}
\text { Det }=(1-2 p)((F-\alpha S 1) q-D+\alpha S 1) *(1-2 q)(F-C 1+K+\alpha S 2-\alpha S 2 p)+p(1-p)(F-\alpha S 1) * q(1-q) \alpha S 2 \\
\operatorname{Tr} J=(1-2 p)((F-\alpha S 1) q-D+\alpha S 1)+(1-2 q)(F-C 1+K+\alpha S 2-\alpha S 2 p)
\end{gathered}
$$

Whether the equilibrium point is an evolutionarily stable strategy is determined by examining the positive and negative values of the determinant DetJ and the trace TrJ of the Jacobian matrix. When Det $J>0$ and $\operatorname{Tr} J<0$, the point is evolutionarily stable. E5 was obtained when $((F-\alpha S 1) q-D+\alpha S 1)=0$ and $(F-C 1+K+\alpha S 2-\alpha S 2 p)=0$. We substituted $E 5$ into $\operatorname{Tr}$ and found that $\operatorname{Tr} J=0$, which does not satisfy the evolutionary stability condition of the strategy. Thus, E5 is an unstable point. To make the gains of both parties of the game closer to reality, the following constraints need to be added: $F-D<0, \alpha S 1-D>0$. To be specific, the construction workers' violation gains are greater than the fines; otherwise, the construction workers have no incentive to violate the regulations. In addition, the construction workers' violation gains are less than the expected accident losses borne by themselves. In addition, $\alpha S 2+K-C 1>0$; that is, once construction workers violate the regulations, the expected consequences of the main contractor should be greater than the cost of conducting safety inspections; otherwise, the main contractor will lose the motivation to conduct safety inspections. However, the administrative penalty for nonstrict supervision is less than the cost of strict supervision, $K-C 1<0$; otherwise, the main contractor will not deregulate. Based on the above conditions, the stability analysis results are shown in Table 3.

Table 3. Stability analysis results.

\begin{tabular}{cccccc}
\hline$(p, q)$ & detj & Sign & trj & Sign & Stability \\
\hline$(0,0)$ & $(\alpha S 1-D)^{*}(-C 1+K+\alpha S 2)$ & + & $(\alpha S 1-D)+(F-C 1+K+\alpha S 2)$ & + & Unstable point \\
\hline$(0,1)$ & $(F-D)^{*}-(-C 1+K+\alpha S 2)$ & + & $(F-D)-(F-C 1+K+\alpha S 2)$ & - & ESS \\
\hline$(1,0)$ & $-(\alpha S 1-D)^{*}(K-C 1)$ & + & $-(\alpha S 1-D)+(K-C 1)$ & - & ESS \\
\hline$(1,1)$ & $-(F-D)^{*}-(K-C 1)$ & + & $-(F-D)-(K-C 1)$ & + & Unstable point \\
\hline
\end{tabular}

As shown in Figure 1, under the constraints, $(0,0)$ is an unstable point, $(0,1)$ is an evolutionary stable point, $(1,0)$ is an evolutionary stable point, $(1,1)$ is an unstable point, and $\left(p^{*}, q^{*}\right)$ is the saddle point, that is, the final system converges between (noncompliant operation, strict supervision by the main contractor) and (safe operation, nonstrict supervision by the main contractor). Ideally, the construction workers operate safely under non-strict supervision by the main contractor. When the initial state is in E1, E2, $E 4$, and E5, the system converges to a bad state, i.e., (non-compliant operation, strict supervision by the main contractor).

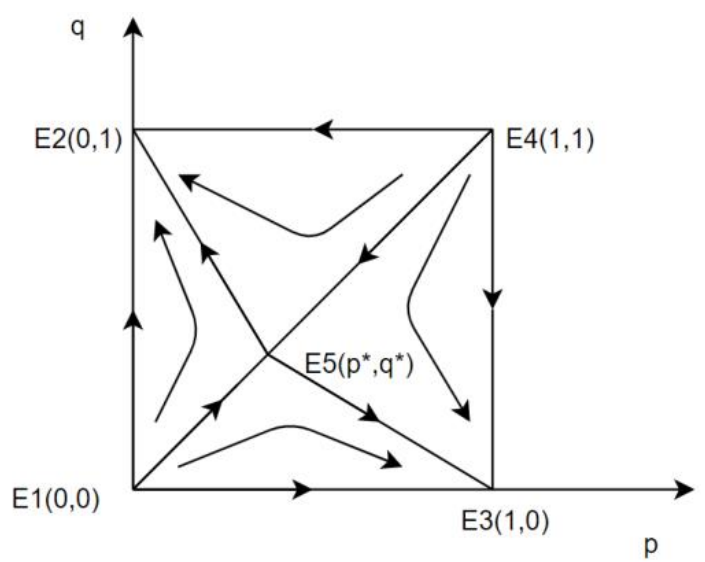

Figure 1. System dynamic evolution diagram. 


\section{Results and Discussion}

In the evolutionary game model, a total of seven parameters can affect the payoffs of both parties of the game. Therefore, these seven parameters were investigated by numerical experiments. In this paper, the parameters were set based on literature review and field research. $p 0$ and $q 0$ represent the possibility of construction workers to choose a safe operation and the possibility of the main contractor to choose strict supervision, respectively, and they are the initial values of the evolution of both parties of the game. $\triangle$ represents the evolutionary direction of the construction workers and is represents the evolutionary direction of the main contractor.

Figure 2 shows the effect of different initial ratios on the evolutionary results. Assuming $p 0=0.5, q 0=0.5, F=0.1, S 1=20, S 2=8, D=0.5, \alpha=0.03, C 1=0.5$, and $K=0.3$, when the initial values are in the region of $E 1, E 2, E 4$, and $E 5$, the system evolves toward the state of (construction workers violate regulations and the main contractor strictly supervises) (Figure 2a). Assuming that $p 0=0.9, q 0=0.4$, and other parameters remain unchanged when the initial values are within the $E 1, E 3, E 4$, and $E 5$ regions, the system evolves toward the state of (construction workers operate safely and the main contractor does not strictly supervise) (Figure 2b).

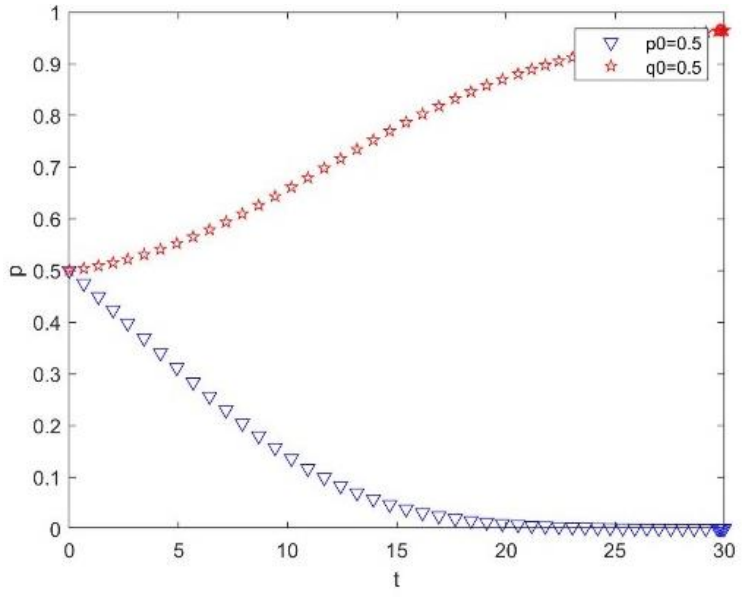

(a) $p 0=0.5, q 0=0.5$

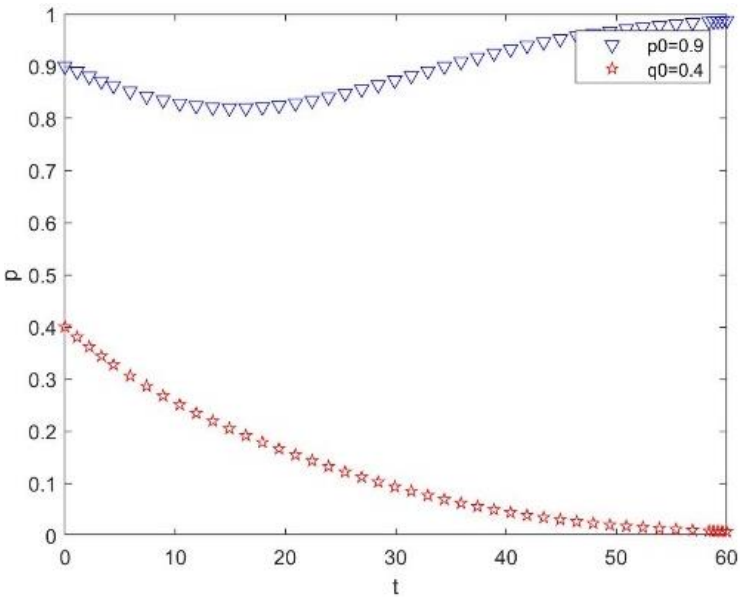

(b) $p 0=0.9, q 0=0.4$

Figure 2. The effect of different initial proportions on the evolution results.

\subsection{The Evolution of Safety Behavior Strategies for Construction Workers}

(1) The effect of violation fines $(F)$ on the evolution results.

As shown in Figure 3, F changes from 0.1 to 0.4. Compared with Figures 2a and 3a shows that the system converges slower with increasing fines, which indicates that as fines increase, construction workers will be more cautious in committing violations. Compared with Figure $2 b$, Figure $3 b$ shows that the increase in penalties changes the evolutionary direction of the system. At high penalties, the system evolves toward the direction of (construction workers violate regulations and the main contractor strictly supervises). This is because $F$ varies from 0.1 to 0.4 and $D=0.5$, i.e., the penalty $F$ is smaller than the gain $D$ of the violation of construction workers. Thus, it can be hypothesized that construction workers will choose to operate safely only when the penalty increases to exceed the amount of labor required for construction workers to comply with safety regulations and the gain of bravado.

The results show that increasing fines has limited effects in restraining construction workers' unsafe behaviors. As the violation fine $F$ increases, the system evolves from the ideal state in which construction workers operate safely and the main contractor does not strictly supervise, to the undesirable state in which construction workers violate and the main contractor strictly supervises. When $F$ increases to a certain level, its further increase 
has almost no effect on the system convergence. Therefore, it is not optimal to take the form of fines to motivate construction workers to operate safely.

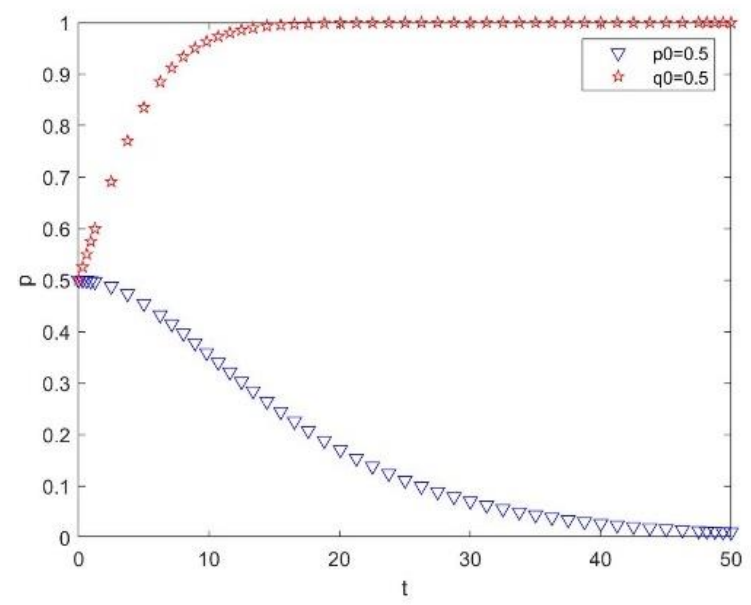

(a) $p 0=0.5, q 0=0.5$

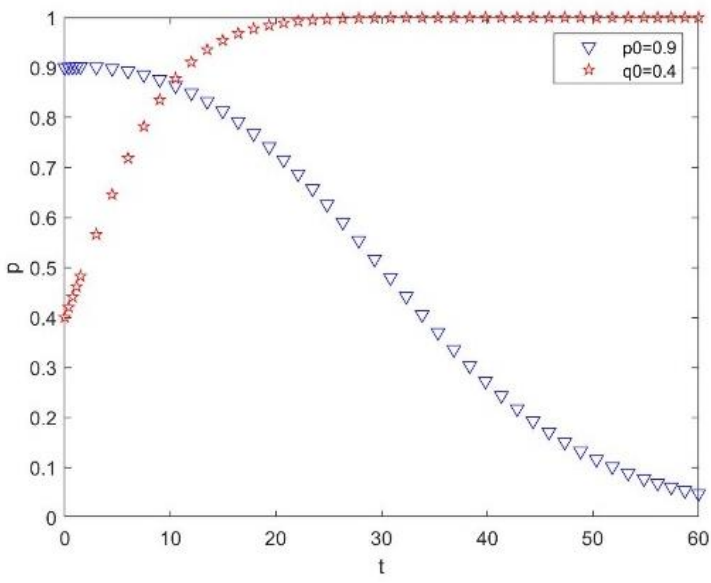

(b) $p 0=0.9, q 0=0.4$

Figure 3. The effect of the violation fine $\mathrm{F}$ on the evolution results.

(2) The effect of the expected accident loss of construction workers (S1) on the evolution results.

From Figure 4, S1 changes from 20 to 40. Compared with Figure 2a, in Figure 4a, construction workers are expected to suffer more accident losses, which changes the evolution of the system. In this case, the system evolves to the ideal state where construction workers operate safely, and the main contractor does not strictly supervise. Compared with Figure $2 b$, in Figure $4 b$, construction workers are expected to suffer more accident losses, which causes the system to converge faster.

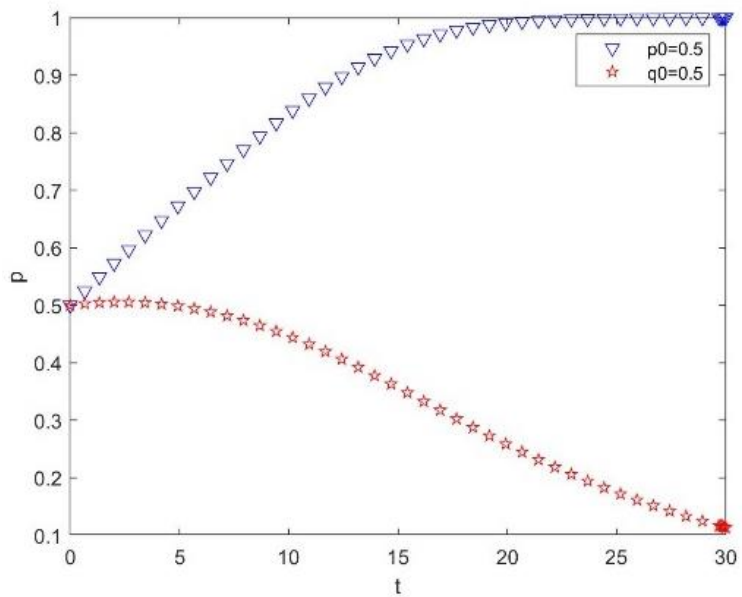

(a) $p 0=0.5, q 0=0.5$

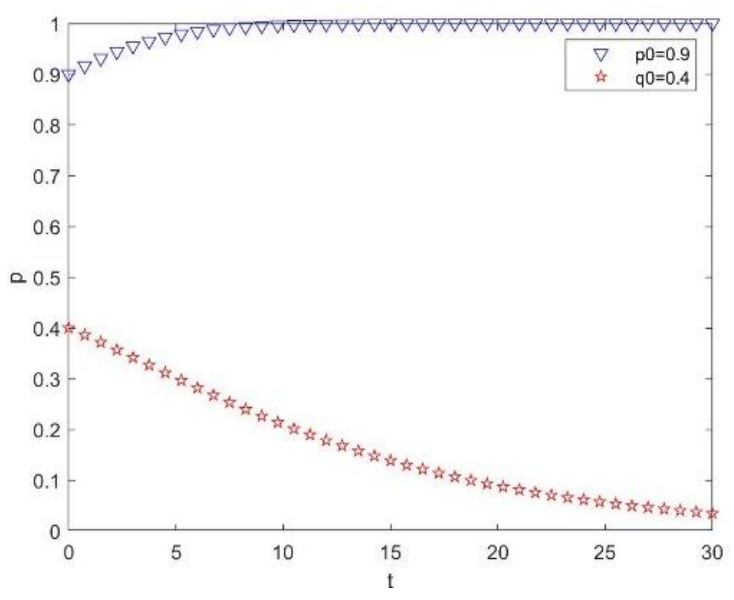

(b) $p 0=0.9, q 0=0.4$

Figure 4. The effect of construction workers' expected accident loss $S 1$ on the evolution results.

Thus, the greater the expected accident losses of construction workers, the stronger the willingness of construction workers to operate safely. The larger the group of construction workers performing safe operations, the better the safety atmosphere during construction, and the lower the willingness of the main contractor to spend extra supervision costs for strict supervision. Therefore, construction workers need to be made aware of the huge costs they will bear when an accident occurs. 
(3) The effect of the gain of non-compliant operation $(D)$ on the evolution results.

From Figure 5, $D$ varies from 0.5 to 0.55. Compared with Figure 2a, in Figure $5 a$, the increase in the amount of labor required by construction workers to comply with safety regulations and the gain of bravado lead to faster convergence of the system. Compared with Figure $2 b$, in Figure $5 b$, the increase in the amount of labor required by construction workers to comply with safety regulations and the increase in the gain of bravado change the evolutionary direction of the system. The system evolves into a bad state where construction workers violate the rules and the main contractor strictly supervises.

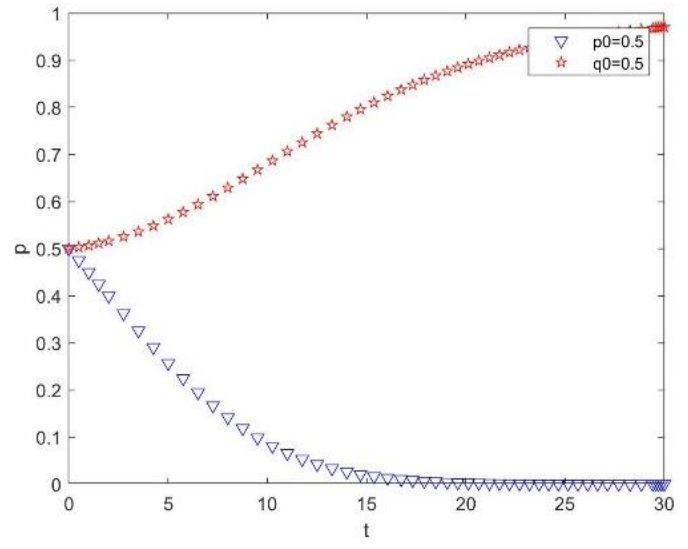

(a) $p 0=0.5, q 0=0.5$

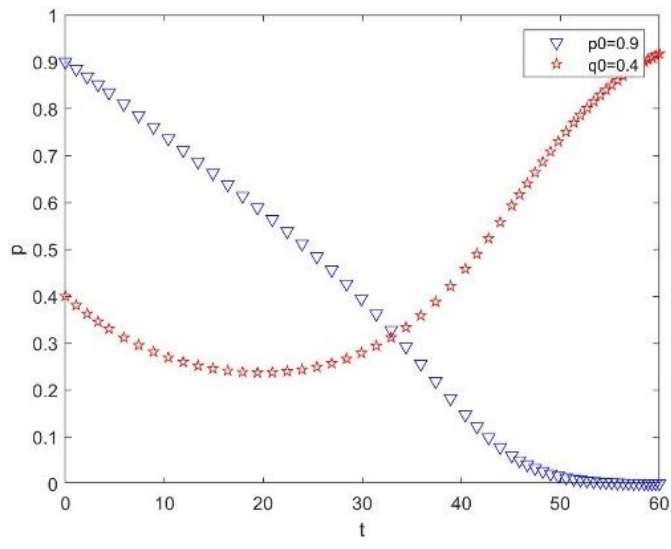

(b) $p 0=0.9, q 0=0.4$

Figure 5. The effect of the amount of labor required for safety behavior and the gain of bravado $D$ on the evolution results.

Therefore, when the amount of labor required to comply with safety regulations is greater, the construction workers' approval of the violation is higher, and the construction workers gain more benefits of bravado, so the gain of the construction workers' violation increases. The larger the value of $D$, the less likely the system will jump out of the "bad lock" state. Therefore, when the safe atmosphere is strong, violations will naturally decrease.

(4) The effect of the probability of the occurrence of safety accident risk $(\alpha)$ on the evolution results.

From Figure 6, $\alpha$ increases from 0.03 to 0.3. Compared with Figure 2a, in Figure 6a, the system evolves toward the direction where the construction workers operate safely, and the main contractor does not supervise strictly. Compared with Figure 2b, in Figure $6 b$, the system evolves toward the direction where the construction workers operate safely, and the main contractor does not supervise strictly.

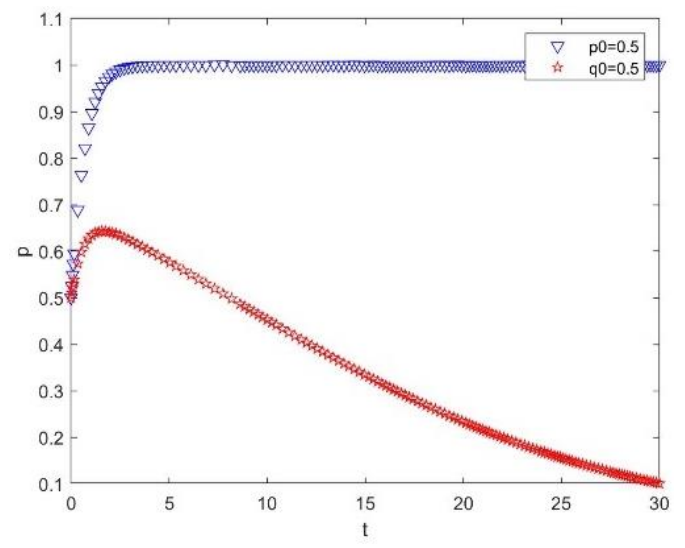

(a) $p 0=0.5, q 0=0.5$

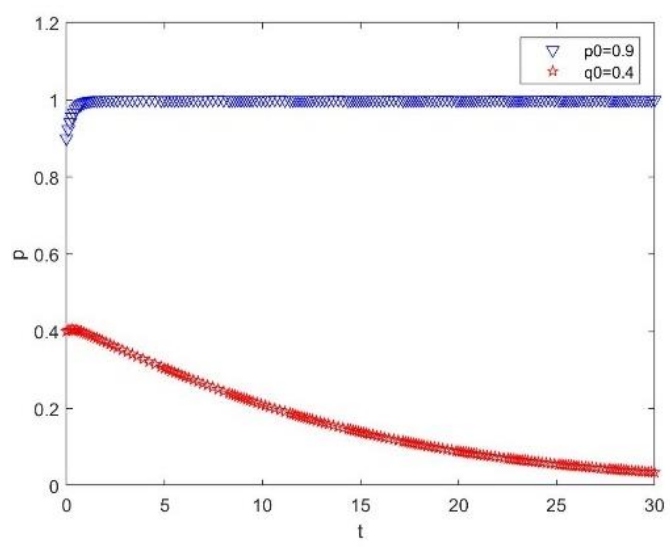

(b) $p 0=0.9, q 0=0.4$

Figure 6. The effect of the probability of the occurrence of safety accident risk $\alpha$ on the evolution results. 
This suggests that the increase in the probability of safety accident risk causes the construction workers to evolve rapidly toward safe operations. When all construction workers operate safely, there is no need for strict supervision of construction workers, so the main contractor converges toward non-strict supervision. The results indicate that when construction workers are aware of unsafe behavior and the potentially severe consequences they may face, few construction workers violate the regulations. Therefore, correcting the fluke and optimism bias of construction workers can enable both parties to objectively view the probability of safety accident risk, which, in turn, effectively facilitates the evolution of construction workers' and the main contractor's strategies toward the ideal state.

Based on the above discussion, both assumptions hold for construction workers. Although construction workers are the most direct beneficiaries of safety management, due to the low safety quality of construction workers, the existence of bravado, herd mentality, and the purpose of saving physical strength and energy, this group has limited rationality to participate in safety behavior.

\subsection{Analysis of the Evolution of Safety Behavior Strategies of the Main Contractor}

(1) The effect of the main contractor's expected accident loss (S2) on the evolution results.

From Figure 7, S2 changes from 8 to 20. Compared with Figure 2a, in Figure 7a, the expected accident loss of the main contractor increases, which makes the system converge faster. Compared with Figure $2 \mathrm{~b}$, in Figure $7 \mathrm{~b}$, the expected accident loss of the main contractor increases, which changes the evolutionary direction of the system. The system evolves into a bad state where the construction workers violate the rules and the main contractor supervises strictly.

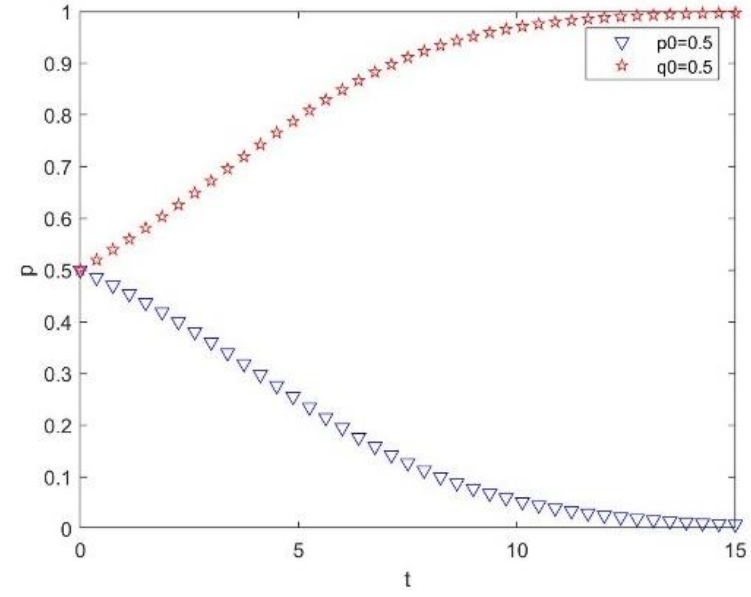

(a) $p 0=0.5, q 0=0.5$

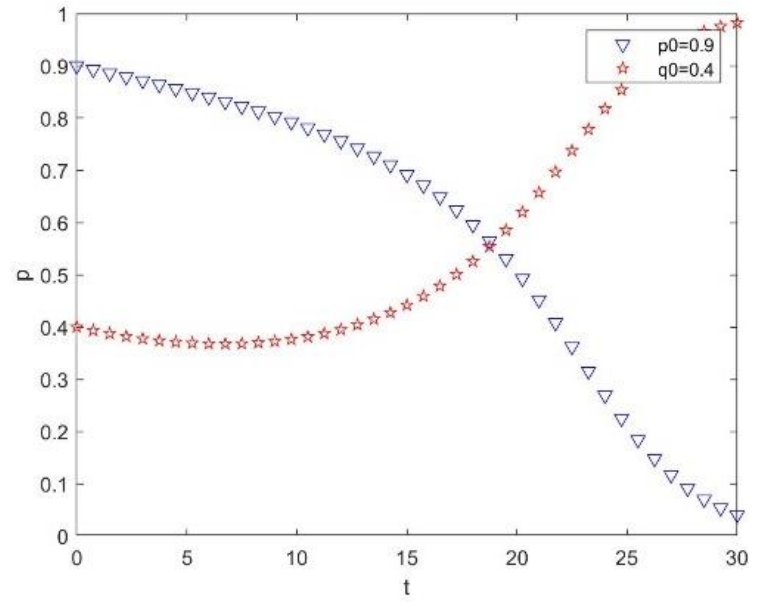

(b) $p 0=0.9, q 0=0.4$

Figure 7. The effect of the main contractor's expected accident loss $S 2$ on the evolution results.

As a result, when the accident losses are expected to be high, the main contractor intensifies safety inspections. This leads to an increase in the intensity and number of inspections, as well as an increase in the number of penalties for construction workers' violations. However, the labor savings and bravado rights of violation always outweigh the fines, so the construction workers' strategy shifts to the violation. As can be seen, the larger the value of $S 2$, the less likely the system is to jump out of the "bad lock" state. Therefore, when the safety atmosphere is strong, the main contractor will also adopt a more humane management style.

(2) The effect of the change in inspection cost (C1) on the evolution results.

From Figure 8, when the inspection cost decreases, there is no significant change in the evolutionary direction. In Figure 8, $\mathrm{C} 1$ changes from 0.5 to 0.4 . Compared with Figure 2a, in Figure 8a, when the inspection cost decreases, the strategy of construction workers converges slowly, the main contractor converges faster, and the evolutionary 
direction does not change. Compared with Figure $2 b$, in Figure $8 b$, the inspection cost decreases, the evolution direction changes, and the system evolves toward the direction of a bad state where the construction workers violate the regulations and the main contractor strictly supervises.

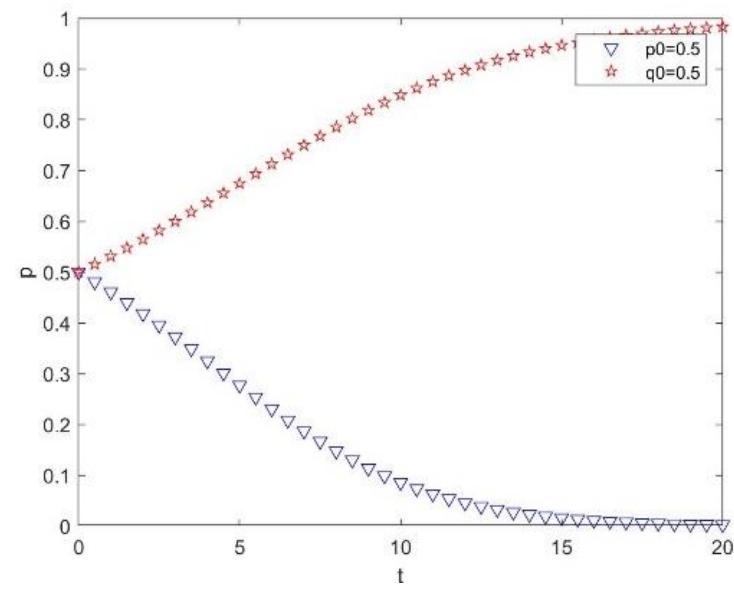

(a) $p 0=0.5, q 0=0.5$

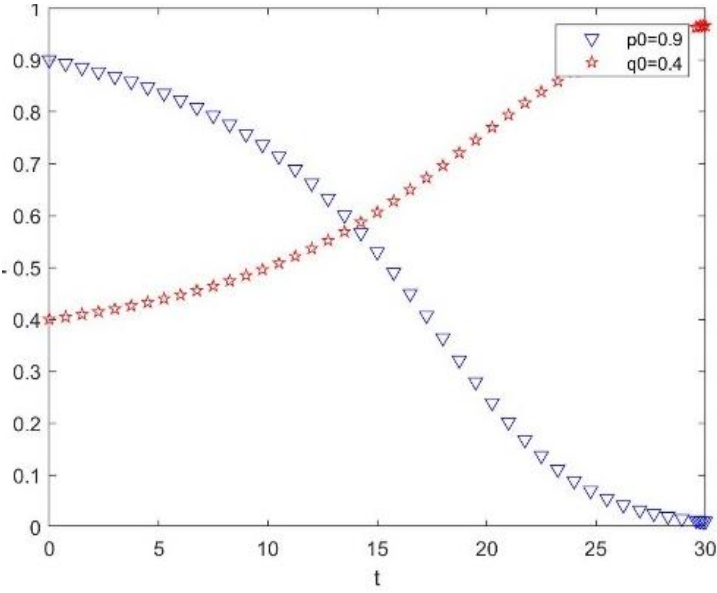

(b) $p 0=0.9, q 0=0.4$

Figure 8. The effect of changes in inspection cost $C 1$ on the evolution results.

These results show that reducing inspection costs cannot effectively improve construction safety. When the main contractor faces low inspection costs, the main contractor is bound to exercise strict supervision and increase fines for the violations by construction workers. The fines for the violations by construction workers are less than the amount of labor saved and the gain of bravado, so the construction workers are gradually evolving to violate the regulations. Therefore, increasing the number of inspections or increasing the intensity of inspections by reducing the inspection costs does not solve the safety problems in the construction process.

(3) The effect of the change in the fine from the owner $(K)$ on the evolution results.

In Figure 9, $K$ changes from 0.3 to 0.4. Compared with Figure 2a, in Figure $9 a$, as $K$ increases, the strategy of the construction workers converges more slowly, the strategy of the main contractor converges more quickly, and the direction of evolution does not change. Compared with Figure $2 b$, in Figure $9 b$, the increase in $K$ changes the evolution direction of the system, and the system evolves toward the direction of a bad state where the construction workers violate the rules and the main contractor strictly supervises.

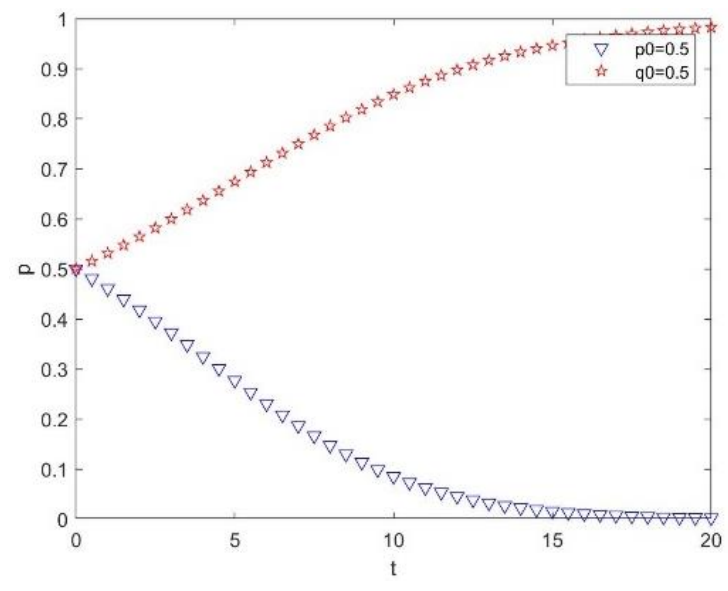

(a) $p 0=0.5, q 0=0.5$

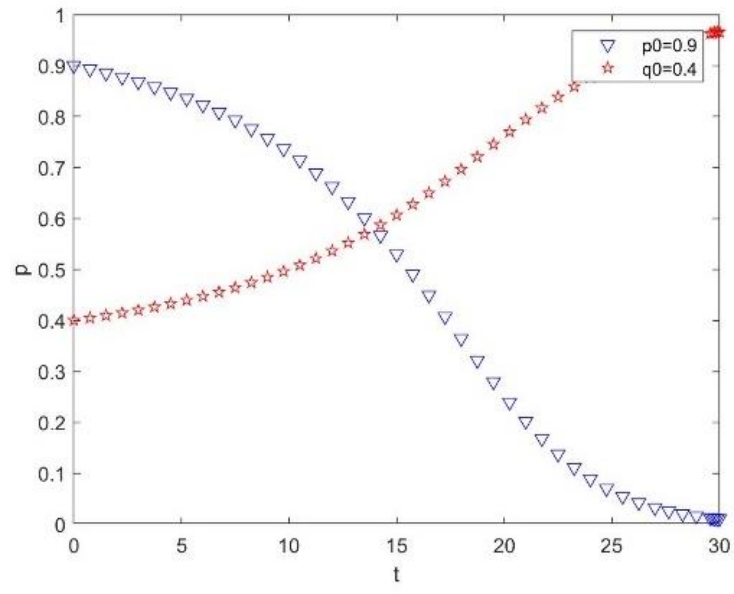

(b) $p 0=0.9, q 0=0.4$

Figure 9. The effect of the change in the fine $K$ on the evolution results. 
These results show that increasing the fine $K$ is not effective in improving construction safety. When the main contractor faces high fines, the main contractor is bound to exercise strict supervision and increase fines for the violations of construction workers. Moreover, the fines for the violations of construction workers are less than the amount of labor saved and the gain of bravado, so the construction workers gradually evolve to violate the regulations. Therefore, increasing the fine $K$ cannot solve the safety problems in the construction process.

Based on the above discussion, two assumptions are valid for the main contractor. Ideally, the main contractor takes strict supervisory measures and will fine construction workers operating in violation of regulations. In addition, the main contractor will relax the supervision because of the duration and cost, so the main contractor is limited rational.

\section{Conclusions and Implications}

In contrast to the existing literature, this paper considers the main contractor and construction workers as the construction safety actors. Therefore, this paper constructs a game model based on the evolution of safety strategies of the main contractor and construction workers, which further extends the application of the game theory in the construction safety management research in theory. Through the analysis of the strategic evolution of the main contractor and construction workers, we found that (non-compliant operation, strict supervision) and (safe operation, non-strict supervision) are two evolutionary stable strategies. Among them, the strategy of (non-compliant operation, strict supervision) is the "bad lock" state. In reality, due to the poor safety quality of construction workers and the weak safety foundation in the construction process, the safety violations of construction workers are serious and basically in a bad state (non-compliant operation, strict supervision).

In addition, previous studies have disagreed on whether fines can effectively improve the safe operation of construction workers. This paper shows through numerical simulations that the use of a "blunt" approach to safety management, in which fines are used to limit construction workers' unsafe behaviors, has limited effect. Moreover, numerical simulation results show that the safety problem cannot be solved by increasing the owner's fines to the main contractor. Increasing the intensity of inspections by reducing the cost of inspections also does not solve the safety problem.

Therefore, taking the profit and loss of each participant as the starting point, studying the evolutionary law of construction workers' safety compliance behavior can enable construction safety management to jump out of the "bad lock" state and provide support for developing effective incentives and restraints on construction safety management to a certain extent. Based on the above research findings, we put forward the following suggestions, which we hope will help to improve construction safety management.

(1) Enhance safety education. Construction workers must be made aware of the serious consequences of accidents and the high likelihood of accidents occurring. It is very important to correct the fluke mentality of construction workers through safety education.

(2) Optimize operating procedures and reduce the amount of labor required to comply with safety regulations. Construction workers are more willing to comply with safety regulations only when the compliance operation is less labor intensive.

(3) Create a good atmosphere of safe production. A good safety atmosphere can reduce the satisfaction of construction workers due to non-compliance operations and will even make them spontaneously resist violations.

Author Contributions: Conceptualization, F.W.; Data curation, F.W.; Formal analysis, F.W. and K.-S.S.; Funding acquisition, H.X.; Investigation, F.W. and K.-S.S.; Methodology, F.W.; Project administration, H.X.; Resources, K.-S.S.; Software, F.W.; Writing—original draft, H.X.; Writing—review \& editing, W.-L.H. All authors have read and agreed to the published version of the manuscript.

Funding: 2020 Major Project about the Philosophy and Social Sciences of Higher education in Jiangsu Province, China (Grant Number: 2020SJZDA043).

Institutional Review Board Statement: Not applicable. 
Informed Consent Statement: Not applicable.

Data Availability Statement: Not applicable.

Acknowledgments: We would like to thank anonymous reviewers for their valuable comments and suggestions for improving this paper.

Conflicts of Interest: The authors declare no conflict of interest.

\section{References}

1. Vinodkumar, M.N.; Bhasi, M. Safety management practices and safety behaviour: Assessing the mediating role of safety knowledge and motivation. Accid. Anal. Prev. 2010, 42, 2082-2093. [CrossRef] [PubMed]

2. Rodrigues, F.; Baptista, J.S.; Pinto, D. BIM Approach in Construction Safety-A Case Study on Preventing Falls from Height. Buildings 2022, 12, 73. [CrossRef]

3. Ibrahim, A.; Nnaji, C.; Shakouri, M. Influence of Sociodemographic Factors on Construction Fieldworkers' Safety Risk Assessments. Sustainability 2022, 14, 111. [CrossRef]

4. General Office of the Ministry of Housing and Urban-Rural Development Notice on Production Safety Accidents in Housing and Municipal Construction in 2019. Available online: https:/ / www.mohurd.gov.cn/ (accessed on 24 February 2022).

5. Su, W.; Gao, X.; Jiang, Y.; Li, J. Developing a Construction Safety Standard System to Enhance Safety Supervision Efficiency in China: A Theoretical Simulation of the Evolutionary Game Process. Sustainability 2021, 13, 13364. [CrossRef]

6. Hallowell, M. Safety risk perception in construction companies in the Pacific Northwest of the USA. Constr. Manag. Econ. 2010, 28, 403-413. [CrossRef]

7. Wu, C.; Fang, D.; Li, N. Roles of owners' leadership in construction safety: The case of high-speed railway construction projects in China. Int. J. Proj. Manag. 2015, 33, 1665-1679. [CrossRef]

8. Gambatese, J.A. Owner Involvement in Construction Site Safety. In Proceedings of the Construction Congress VI, Orlando, FL, USA, 20-22 February 2000.

9. Hinze, J. Construction Safety; Prentice-Hall, Inc.: Upper Saddle River, NJ, USA, 2006.

10. He, B.; Zhang, S.; Zha, J. On the Allocation of Liabilities for Safety among Construction Contract Partie. China Civ. Eng. J. 2004, 37, 101-105. [CrossRef]

11. Math. Graphics. Programming. Available online: https://www.mathworks.com/products/matlab.html (accessed on 21 January 2022).

12. Guo, H.; Yu, Y.; Skitmore, M. Visualization technology-based construction safety management: A review. Autom. Constr. 2017, 73, 135-144. [CrossRef]

13. Zhang, S.; Sulankivi, K.; Kiviniemi, M.; Romo, I.; Eastman, C.M.; Teizer, J. BIM-based fall hazard identification and prevention in construction safety planning. Saf. Sci. 2015, 72, 31-45. [CrossRef]

14. Asah-Kissiedu, M.; Manu, P.; Booth, C.A.; Mahamadu, A.-M.; Agyekum, K. An Integrated Safety, Health and Environmental Management Capability Maturity Model for Construction Organisations: A Case Study in Ghana. Buildings 2021, 11, 645. [CrossRef]

15. Chan, D.W.M.; Cristofaro, M.; Nassereddine, H.; Yiu, N.S.N.; Sarvari, H. Perceptions of Safety Climate in Construction Projects between Workers and Managers/Supervisors in the Developing Country of Iran. Sustainability 2021, 13, 10398. [CrossRef]

16. Wang, X.; Liu, Y.; Qiu, K.; Shen, F. Research on evolutionary game for construction workers participation in safety management. China Saf. Sci. J. 2016, 26, 105-154.

17. Seo, H.-C.; Lee, Y.-S.; Kim, J.-J.; Jee, N.-Y. Analyzing safety behaviors of temporary construction workers using structural equation modeling. Safety Science 2015, 77, 160-168. [CrossRef]

18. Hsu, W.-L.; Chen, Y.-S.; Shiau, Y.-C.; Liu, H.-L.; Chern, T.-Y. Curriculum Design in Construction Engineering Departments for Colleges in Taiwan. Educ. Sci. 2019, 9, 65. [CrossRef]

19. Liu, S.; Mei, Q.; Zhang, Z. On the Evolution of Workers' Safety Compliance Behavior in Small and Medium-Size Enterprises. J. Syst. Manag. 2012, 21, 275-282. (In Chinese)

20. Notice on the Results of the Investigation and Treatment of the "12-16" Fatal Object Strike Accident at Nanjing BoCai Construction Engineering Corporation. Available online: https://nanjing.gov.cn/index.html (accessed on 24 February 2022).

21. Ma, Y. Psychological analysis and control countermeasures of intentional unsafe behavior of coal mine employees. Shenhua Technol. 2010, 8, 10-13+29. (In Chinese)

22. Wang, J.; Qin, Y.; Zhou, J. Incentive policies for prefabrication implementation of real estate enterprises: An evolutionary game theory-based analysis. Energy Policy 2021, 156, 112434. [CrossRef]

23. Coninx, K.; Deconinck, G.; Holvoet, T. Who gets my flex? An evolutionary game theory analysis of flexibility market dynamics. Appl. Energy 2018, 218, 104-113. [CrossRef]

24. Sun, Y. Research on Self-Interest Safety Management Mechanism of China's Construction Firms. Master's Thesis, Dongbei University of Finance and Economics, Dalian, China, 2005. Available online: https: $/ / \mathrm{kns} . \mathrm{cnki} . n e t / \mathrm{kcms} / \mathrm{detail} / \mathrm{detail}$.aspx?dbcode= CMFD\&dbname=CMFD2007\&filename=2006134105.nh\&uniplatform=NZKPT\&V=WY-nCivAV_VGbiNu9VoBTPoONa58rbYs8Py86DY1zDaGNhnLThplRDc9vuADeWW (accessed on 25 February 2022). 
25. Chen, B. Study Government Regulation of Construction Safety Research and Countermeasure Analysis. Master's Thesis, Zhejiang University, Hangzhou, China, 2009. Available online: https://kns.cnki.net/kcms/detail/detail.aspx?dbcode=CMFD\& dbname=CMFD2009\&filename=2009096513.nh\&uniplatform $=$ NZKPT\&v=MA68ZtEs6FA3a7kGJ38i3jL9TsTAhnyNSJT-ftulR16 7QEmxoQ2IV_a00tyGDcOX (accessed on 25 February 2022).

26. Xiao, X.; Sun, Y. The Game Analysis of China's Construction Safety Regulation. Rev. Ind. Econ. 2009, 2, 50-63.

27. Zeng, X.; Chen, J. Game analysis and policy commendation of the supervision on the construction safety about construction enter-prises. Constr. Econ. 2013, 5, 93-97.

28. Chen, Y.; Wang, J.; Huang, X. Stability Analysis of Tunnel Construction Safety Supervision Strategy Based on SD Model. J. Syst. Sci. 2021, 29, 127-131.

29. Feng, Q.; Shi, X.-J.; Xu, W. Power Rent-Seeking Governance in Safety Supervision System of Projects: Based on Evolutionary Game Model among the Subjects. Chin. J. Manag. Sci. 2015, 23, 9-14.

30. Cheng, M. Research on Construction Safety Supervision Based on Evolutionary Game Theory. Oper. Res. Manag. Sci. 2011, 6, 210-215.

31. Chen, Y.; Lyu, Y.; Chai, F.; Wang, X. Evolutionary Game Analysis of Unsafe Behavior of Construction Workers from the Perspective of Dynamic Incentives. Saf. Environ. Eng. 2020, 27, 197-203. [CrossRef]

32. Ma, G.; Wu, Z.; Jia, J.; Shang, S. Safety risk factors comprehensive analysis for construction project: Combined cascading effect and machine learning approach. Saf. Sci. 2021, 143, 105410. [CrossRef]

33. Yi, X.; Wu, J. Research on Safety Management of Construction Engineering Personnel under "Big Data + Artificial Intelligence". Open J. Bus. Manag. 2020, 8, 1059-1075. [CrossRef]

34. Dasandara, S.P.M.; Dissanayake, P. Limiting reasons for use of personal protective equipment among construction workers: Case studies in Sri Lanka. Saf. Sci. 2021, 143, 105440. [CrossRef]

35. Chen, Y.; Zeng, Q.; Zheng, X.; Shao, B.; Jin, L. Safety supervision of tower crane operation on construction sites: An evolutionary game analysis. Saf. Sci. 2021, 105578. [CrossRef]

36. Ni, S.; Zou, S.; Chen, J. Evolutionary Game Model of Internal Threats to Nuclear Security in Spent Fuel Reprocessing Plants Based on RDEU Theory. Sustainability 2022, 14, 2163. [CrossRef]

37. Huang, Q.; Wang, J.; Ye, M.; Zhao, S.; Si, X. A Study on the Incentive Policy of China's Prefabricated Residential Buildings Based on Evolutionary Game Theory. Sustainability 2022, 14, 1926. [CrossRef]

38. Zhu, C.; Fan, R.; Luo, M.; Zhang, Y.; Qin, M. Simulating policy interventions for different quota targets of renewable portfolio standard: A combination of evolutionary game and system dynamics approach. Sustain. Prod. Consum. 2022, 30, 1053-1069. [CrossRef] 